\title{
We Need to Talk
}

\section{How a Con Con Can Secure Hawai'i's Post-COVID Future}

\author{
Colin D. Moore
}

In Hawai' $i$, nobody tells better stories than our kūpuna. And if you love politics, nothing is better than listening to those told by seasoned politicians. These are the folks who can recall precisely their share of the vote in decades-old elections. They can tell you how they stood in the pouring rain, sign-waving for hours, after going door to door in Makiki, soaked in sweat, just to talk with every voter. What's more, they can tell you why it mattered.

But if you listen to their stories of the art and gamesmanship of politics for long enough, these masters of legislative deal-making will often confess that they're worried. They will explain that a state that once championed radical legislation such as the 1974 Prepaid Health Care Act-a law that guaranteed health care for most working people- has become too cautious, hidebound, and gutless to do bold things anymore. They think Hawai' $i$ is stuck.

Even before the COVID-19 crisis, Hawai'i faced some daunting challenges: limited affordable housing, a tourism industry that exploited the population, and the exodus of its young people to cities that promised more opportunities. Add the costs to maintain infrastructure, adapt to sea level rise, and pay for public employee pension obligations - costs that one estimate puts at $\$ 88$ billion-and you can understand why some Hawai'i political veterans fear for our future (Troubled Waters).

To confront these challenges — and those presented by COVID-19-we need to rethink our policymaking process. And to do that, we need to hold a Con Con. Let me explain.

Hawai'i has a unique constitutional provision shared by only five other states. Every ten years, this question must appear before voters on the ballot: Shall there be a convention to propose a revision of or amendments to the Constitution?

Often referred to as a "Con Con," the last constitutional convention occurred over forty years ago. That legendary 1978 Con Con established new environmental protections and led to the creation of the Office of Hawaiian Affairs.

When the question appeared on the ballot in 2018, I felt hopeful. I was curious what would happen if everyday citizens had a chance to think through its 
implications. I wasn't alive in 1978, but I'd heard the stories and read the transcripts from the '78 Con Con, and I believed that it fundamentally changed Hawai' $i$ for the good.

During the fall of 2018, the University of Hawai'i Public Policy Center, which I direct, tried an experiment. We set up a "citizens' jury" to allow a broad spectrum of people to consider the implications of holding a Con Con. Drawn mainly from Honolulu neighborhood boards, the participants heard arguments for and against the process. In the end, a strong majority supported the Con Con.

A month later, the Con Con ballot question failed. Only 23 percent of the electorate voted yes - and most voters never had the chance to seriously consider it. The vast majority of local pressure groups, including most unions and conservation groups, were opposed because of concerns that shadowy "mainland interests" would undermine our current constitution and the environmental protections and collective bargaining rights it provides.

I was surprised at how depressed I felt by this result. Unlike what I heard in our citizens' jury, the arguments from professional lobbyists came from a place of fear-of what might be lost, rather than the possibilities to change our system of government for the better.

We missed our chance in 2018, but it's not too late. If we want a brighter future for Hawai'i after COVID-19, we need to change our political system. A Con Con can provide a forum for a community-wide discussion of values and priorities. It might also help us tackle some of the problems that result from our broken policymaking process.

Trust and Public Engagement. Hawai' $i$ has the lowest voter turnout rate in the nation. In the 2018 general election, only 44 percent of eligible voters cast a ballot. Voting isn't the only way to participate in politics, of course, and there is often too much handwringing from pundits like me about our low turnout rates. But it is a symptom of something deeper: a lack of trust, and a sense that there's really no point in participating in electoral politics. In 2018, the UH Public Policy Center found that only 30 percent trusted our state government to do what was in the public's interest most of the time. This is not a sign of a healthy democracy.

Political Competition. In Hawai' $i$ we lack the vigorous political competition that is a hallmark of the democratic process. The dominance of the Democratic Party has only increased in recent years after the Republican Party's dramatic shift to the right. Today, with a few notable exceptions, Republicans in Hawai'i can barely field credible candidates for public office. Although some may cheer the party's demise, what's replaced two-party competition is a system of legislative factions held together by personal relationships or political favors. With no real opposition, there is no need for public debate. The result is a policymaking process that is nearly opaque and almost impossible for regular citizens to follow.

Policy Responsiveness. I'll be blunt. Hawai' i may be ruled by Democrats, but the state's politics haven't been progressive for a very long time. That the vast majority of our elected leaders come from affluent backgrounds means that they are less 
likely to support policies that benefit the poor. Hawai' $i$ still has no publicly-funded pre-kindergarten education or paid family leave for working families. Our regressive general excise tax indiscriminately taxes all consumers regardless of income, and places the highest tax burdens on low-income families in the nation. This even though in nearly every poll, Hawai'i families put issues such as affordable housing and education on the top of their lists.

How might we solve these problems? Despite the faith that some put in the private sector, we should resist replacing an unresponsive legislature with unaccountable business groups. Avoiding politics is not the answer. As policy theorist Deborah Stone has written, "In the process of articulating reasons, we show each other how we see the world" (380). What we need instead is a way to talk about how to balance values and needs that we all share, such as equity and efficiency, liberty and justice.

That is what happens at a Con Con. It is the only forum that provides an opportunity to take a comprehensive and holistic approach to improve government and address our most intractable policy challenges.

What changes might we make? Here are a few suggestions.

Publicly-Financed Elections. Although Hawai'i already has some public financing for candidates, this system could be expanded dramatically. If we want more candidates from diverse backgrounds, we need to expand the opportunities for them to get their message out. Money in politics is not the problem. It's that the money comes from a small number of powerful interests.

Nonpartisan Elections. When nearly every member of the legislature is a Democrat, party labels no longer provide much information to voters. In a small state where the ideological orientations of voters often don't map well onto the advanced culture wars raging in the continental US, we should consider a nonpartisan legislature. Coupled with a primary process that would allow the top two vote-getters to advance to the general election, this might lead to a new set of diverse elected voices less beholden to the power structures of one political party.

A Full-Time Legislature. The current requirement for a 60-day legislative session is indefensible. The result is a scramble for attention that favors organized lobbyists, while good bills are forced to wait, sometimes for years, for a serious hearing. By allowing the legislature to meet throughout the year, we could end this madness and increase the time for every sensible bill to be properly studied.

These are the kinds of changes that could be coupled with other guarantees at a new Con Con. What about a constitutional right to housing? Guaranteed access to higher education? A Con Con would also offer an opportunity to expand and clarify the Native Hawaiian rights that came out of the 1978 convention. Such ideas could be debated by delegates elected from across the state.

A Con Con is about real community engagement-and only that can create the trust and legitimacy necessary to reform our policymaking process.

We need to talk, Hawai' i. A Con Con will provide the space to consider our post-COVID future. 


\section{Works Cited}

Stone, Deborah. Policy Paradox: The Art of Political Decision Making. 2nd ed., W. W. Norton, 1997.

Troubled Waters: Charting a New Fiscal Course for Hawai' $i$. Hawai' i Executive Conference, 2 Oct. 2019, https://www.documentcloud.org/documents/6476457-HEC-

Government-Report-FINAL.html\#document/p1.

Colin D. Moore is an Associate Professor, the Director of the Public Policy Center, and the Chair of the School of Communications at the University of Hawai'i at Mānoa. He serves as a political analyst for Hawai' i News Now. 